\title{
The poverty-assistance paradox
}

\author{
Béla Janky ${ }^{\mathrm{a}, \mathrm{b}, *}$, Dániel Varga ${ }^{\mathrm{a}}$ \\ ${ }^{a}$ Budapest University of Technology and Economics, Department of Sociology and Communication, Hungary \\ ${ }^{\mathrm{b}}$ Hungarian Academy of Sciences, Institute of Sociology, Hungary
}

\section{H I G H L I G H T S}

- We introduce a simple model of preferences on welfare transfers.

- Recipient's wealth is a signal of needs and deservingness.

- Rational voters use a realistic function of wealth generation.

- A paradox may arise: the poorer the recipient is, the less transfer he/she will get.

- Future research: the negative impact of targeting on public support for welfare.

\section{A R T I C L E I N F O}

\section{Article history:}

Received 28 August 2012

Received in revised form

3 June 2013

Accepted 4 June 2013

Available online 10 June 2013

\section{JEL classification:}

H8

I3

Keywords:

Welfare preferences

Social preferences

Welfare transfers

\begin{abstract}
A B S T R A C T
We present a model of preferences on welfare transfers, which incorporates the recipient's wealth as a signal of needs and deservingness. We show that a paradox may arise: the poorer the recipient is, the less transfer he/she will get. Implications might include the negative impact of targeting assistance to the poorest on public support for welfare.
\end{abstract}

(C) 2013 Elsevier B.V. All rights reserved.

\section{Introduction}

The variation of welfare regimes in the advanced economies has attracted considerable scholarly interest in the past few decades. Students of various disciplines seem to agree that the public image of the poor is key to the understanding of diverging institutional frameworks.

We follow this line, and present a model of compassionate voters' preferences on welfare transfers to the poor. The model shows that the uncertainty about the recipient's behavior might lead to paradoxical preferences: the poorer the recipient is, the less transfer he/she would get. The paradox, we conjecture, may contribute to some kind of institutional framing effects discussed in the social policy literature.

\footnotetext{
* Correspondence to: Budapest University of Technology and Economics, Department of Sociology and Communication, H-1111 Budapest, Egry Jozsef 1. E715., Hungary. Tel.: +36 304915581.

E-mail addresses: janky@eik.bme.hu, belu72@gmail.com (B. Janky).
}

As far as the behavioral assumptions are concerned, we draw on those theories and evidence which point to "deservingness" as a key concept in voters' minds. The voter (She) decides on the optimal level of transfer for any poor individual (He). She cannot observe the recipient's efforts, but is informed about his wealth, which indicates material needs, but also provides noisy information on his efforts. His distress fuels her compassion, but, at the same time, sends a negative signal about his efforts. This ambiguity, in turn, may give rise to the paradox we discuss below.

\section{The problem}

The puzzle we address is posed by findings in polls which, according to Larsen (2006), indicate that the targeting of povertyalleviating institutions to the very poorest might have an adverse effect on public opinion: a smaller, poorer group of potential beneficiaries implies a worse image of the poor and lower support for welfare than a larger, more mixed set of welfare recipients.

Our model might lay the ground for understanding the above results and the narrative arguments behind them. It is a much 
simpler and less ambitious analysis than the ones presented by Alesina and Angeletos (2005), Benabou and Tirole (2006), and Di Tella and Dubra (2013), which investigated the simultaneous developments of beliefs, efforts, and redistribution. We only concentrate on welfare transfers to the poor, and aim at pointing to mechanisms which stem from recipients' living standards as a signaling device.

\section{The model}

Our approach partly relies on Besley and Coate's (1992) model of preferences on welfare transfers to the poor. Like their model, we assume that voters intend to help distressed and deserving individuals. That is, they support transfers which compensate for poverty due to bad luck, but are reluctant to relieve distress which stems from lack of effort. Some more comprehensive models on redistributive preferences adopt similar assumptions (e.g., Alesina and Angeletos, 2005; but see Di Tella and Dubra, 2010 for a different approach), and a recent wave of economic research argues in favor of their empirical validity (e.g., Fong and Luttmer, 2011; Konow, 2010). A great many findings of polls also indicate the popular concern for deservingness (e.g., Gilens, 1999; Lepianka et al., 2009). We also follow Besley and Coate's (1992) approach by assuming that voters are uncertain about the recipients' behavioral traits.

However, we introduce the level of the recipient's wealth as a key information for the voter's decision on the optimal level of transfer. Moreover, unlike their model, we focus on the pure effects of social preferences.

Let us start with a simple model of the compassionate voter's preferences in society $S$ :

$U_{i}=V\left(W_{i}\right)+\sum_{j} D_{i j}\left(W_{j}, E_{j}, F_{j}\right)$,

where $i, j \in S$, and $i \neq j . W$ is a measure of living standards, and $E_{j}$ accumulates all the multiplicative factors of $W_{j}$ for which $i$ imposes responsibility on $j$ (e.g., personality traits such as effort). $F_{j}$, on the other hand, accumulates multiplicative factors the voter is ready to compensate $j$ for (e.g., situational factors such as (mis)fortune). The voter assumes that $W=E F .^{1}$

From now on we concentrate on the pure effects of social preferences, namely $D_{i j}$, which expresses the voter's (dis)utility stemming from observing the distress of misfortunate fellow citizens. In this way, we simplify our analysis without altering our qualitative results; and, more importantly, we make as clear as possible that the paradox we show can emerge fully independently of 'the taxpayer's resentment'.

The voter in our model cares only about the poorest and misfortunate ones; namely, those who fall below the poverty line, $W_{p}$, and whose efforts would justify higher living standards than they have. Consider first the full information environment. Observing a fellow citizen, her (dis)utility function takes the following form:

$D_{i j}=0 \quad$ for $W_{j} \geqq E_{j} F_{\text {med }}$ or $\quad W_{j} \geqq W_{p}$, and

$D_{i j}=\max \left(W_{j}-E_{j} F_{\text {med }}, W_{j}-W_{p}\right)$ for $W_{j}<E_{j} F_{\text {med }}$

and $W_{j}<W_{p}$

where $F_{\text {med }}$ is the median value of 'fortune' in $S$. That is, the compassionate voter derives disutility from observing a poor individual who is less fortunate than the majority of the population in $S$ (see Alesina and Angeletos, 2005). Note that at any given level of

\footnotetext{
1 Note the difference between this approach and those of for example Alesina and Angeletos (2005), or Di Tella and Dubra (2010).
}

a poor person $j$ 's 'misfortune' (where $F_{j}<F_{\text {med }}$ ), the fall in $i$ 's utility increases with the efforts of $j$. This reflects the voter's concern for deservingness. It is plausible to assume that in a modern affluent society $E_{\text {med }} F_{\text {med }}>W_{p}$. We do not exploit this assumption below, but it ensures that the voter ignores only such poor who are 'lazier' than the majority of the society $\left(E_{j}<E_{\text {med }}\right)$. One can also see from (1) that $i$ 's pure social preferences imply that the optimal level of transfers to $j$ is equal to $\max \left(\min \left(E_{j} F_{\text {med }}-W_{j}, W_{p}-W_{j}\right), 0\right)$. Note that if a poor enough individual $j$ with personality traits $E_{j}$ is given, then the voter's social preferences never justify any decrease of transfers as $j$ 's livings standards deteriorate in the full information environment.

A crucial assumption of our model, however, is that the voter cannot observe $E_{j}$ and $F_{j}$ directly. She observes, on the other hand, $W_{j}$, and has prior beliefs on the distributions $E$ and $F$. Based on her priors and the observed $W_{j}$, the voter can estimate the posterior probability distributions of $j$ 's 'effort' and 'fortune'. Those posteriors can be used, in turn, to determine the optimal level of transfers. In the most general case, this takes the form of an expected utility maximization over the possible values of $F_{j}$. We can state a general theorem in this framework. In this letter, however, we deal with the easily tractable special case where the preferred level of compensation is determined simply by the median of $j$ 's posterior effort, $\hat{E}_{j}\left(W_{j}, E, F\right)$. That is, the voter uses a point estimation to calculate the optimal level of transfers.

We assume that the voter is informed about the scholarly observation that the log-normal distribution is a good fit for the empirical wealth distribution for much of the wealth range (Chatterjee et al., 2007). In the voter's model, $E$ and $F$ are independent log-normal distributions whose product, $W$ (which is log-normal itself), approximates the observed distribution of living standards in the society. Multiplicative constants do not affect our model, so we can assume without loss of generality that $E_{\text {med }}=F_{\text {med }}=1$. Then, based on $i$ 's social preferences, beliefs, and observation, one can express the optimal level of transfers to $j$ as follows:

$T\left(W_{j}\right)=\max \left(\min \left(\hat{E}_{j}-W_{j}, W_{p}-W_{j}\right), 0\right)$.

Let us denote the logarithms of our variables with lower-case versions. $w=e+f$. Note that we assume without loss of generality that $e \sim N\left(0, \sigma_{e}^{2}\right)$ and $f \sim N\left(0, \sigma_{f}^{2}\right)$. The parameters $\sigma_{e}$ and $\sigma_{f}$ represent the voter's prior beliefs on the relative strength of the roles of $E$ and $F$. $w \sim N\left(0, \sigma_{e}^{2}+\sigma_{f}^{2}\right)$, so $\sigma_{w}^{2}=\sigma_{e}^{2}+\sigma_{f}^{2}$ is observable. Given this constraint, any belief on the variances of $E$ and $F$ is compatible with rationality. We define the voter's perceived meritocracy index $\mu$ as $\sigma_{e}^{2} / \sigma_{w}^{2}$.

After introducing the meritocracy index, we can formulate our theorem on the paradox (subscript $j$ is left out for convenience).

Theorem 1 (Existence of Poverty-Assistance Paradox). Consider any $W<W_{p}^{1 / \mu}$. Then, $T(\epsilon W)<T(W)$ for any $0<\epsilon<1$ iff $W<$ $\mu^{1 /(1-\mu)}$.

The ratio of the population affected by the paradox cannot be given in a closed form. Numerical calculations show that it strongly and positively correlates with inequality, and (within the constrains given by $W_{p}$ ) less strongly with the perceived meritocracy.

\section{Proof of the theorem}

In our simple model, the median posterior effort has a particularly clean form:

Proposition 1. $\hat{E}=W^{\mu}$. 
Proof. Working with the Gaussian joint probability distribution $(e, f)$, it is easy to prove that, conditioned on observing $w=e+f$, the posterior distribution of $e$ is again a Gaussian $N\left(m(w), d^{2}\right)$, with parameters

$d^{2}:=\frac{1}{\frac{1}{\sigma_{e}^{2}}+\frac{1}{\sigma_{f}^{2}}}=\frac{\sigma_{e}^{2} \sigma_{f}^{2}}{\sigma_{w}^{2}}$

and

$m(w):=\frac{d^{2}}{\sigma_{f}^{2}} w=\frac{\sigma_{e}^{2}}{\sigma_{w}^{2}} w=\mu w$.

From this we can indeed conclude that

$\hat{E}=\exp m(\log W)=W^{\mu}$.

Proof of Theorem 1. We claim that $T(W)$ has a unique maximum at $W_{\max }:=\mu^{1 /(1-\mu)}$. In our theorem, we only consider the case where $W^{\mu}=\hat{E}<W_{p}$. In this case, $T=W^{\mu}-W$. Taking the derivative of $W^{\mu}-W$, it is easy to see that it has a single positive root at $W_{\max }$, and that the second derivative is positive there.

\section{Conclusions}

Our analysis sheds light on the implications of incorporating recipients' living standards as a signaling device into models on welfare preferences. The emergence of the poverty-assistance paradox we have described is highly dependent on the way beliefs and preferences are modeled. We have shown that, given our model on preferences, rational beliefs can easily produce the paradox.

Our model on preferences lacks a direct preference for securing a minimal income for anyone-irrespective of his behavior. It also lacks a direct preference for punishing low effort. The former assumption could inhibit the emergence of the paradox, and the latter one would assist it.

Our research in progress deals with three important generalizations of the base result: (i) additional observed and/or hidden variables, (ii) not fully independent variables, and (iii) optimization within the framework of expected utility maximization. It can be shown that, even with these generalizations, the paradox arises under very plausible assumptions.
We have not presented a model of voting on redistribution. We conjecture, however, that incorporating the assumptions leading to the paradox into a political economy model could help in understanding the adverse effects of targeting public assistance to the poorest groups on welfare preferences better (see Larsen, 2006). The intuition is straightforward: targeting to the very poor may create a group of potential beneficiaries whose members are, individually, less supported by the representative voter than less distressed low-status persons outside this small group. Nonetheless, a strong effect of 'taxpayer resentment' would surely complicate any such model, since targeting saves taxpayers' money.

\section{Acknowledgments}

Support provided by the research projects K76223 and K83887 of the Hungarian Scientific Research Fund and the MTA Bolyai Scholarship is gratefully acknowledged. We are indebted to Ágnes Horváth and an anonymous referee for their comments on an earlier version of the paper.

\section{References}

Alesina, A., Angeletos, G., 2005. Fairness and redistribution. American Economic Review 95 (4), 960-980.

Benabou, R., Tirole, J., 2006. Belief in a just world and redistributive politics. Quarterly Journal of Economics 121 (2), 699-746.

Besley, T., Coate, S., 1992. Understanding welfare stigma: taxpayer resentment and statistical discrimination. Journal of Public Economics 48 (2), 165-183.

Chatterjee, A., Sinha, S., Chakrabarti, B.K., 2007. Economic inequality: is it natural? Current Science 92 (10), 1383-1389.

Di Tella, R., Dubra, J., 2010. A note on fairness and redistribution. Harvard Business School Working Paper 11-059.

Di Tella, R., Dubra, J., 2013. Fairness and redistribution: comment. American Economic Review 103 (1), 549-553.

Fong, C.M., Luttmer, E.F.P., 2011. Do fairness and race matter in generosity? Evidence from a nationally representative charity experiment. Journal of Public Economics 95 (5-6), 372-394.

Gilens, M., 1999. Why Americans Hate Welfare. University of Chicago Press, Chicago.

Konow, J., 2010. Mixed feelings: theories of and evidence on giving. Journal of Public Economics 94 (3-4), 279-297.

Larsen, C.A., 2006. The Institutional Logic of Welfare Attitudes: How Welfare Regimes Influence Public Support. Ashgate, Hampshire.

Lepianka, D.A., van Oorschot, W.J.H., Gelissen, J.P.T.M., 2009. Popular explanations of poverty: a critical discussion of empirical research. Journal of Social Policy 38 (3), 421-438. 